RESEARCH REPORT

\title{
Early life predictors of childhood intelligence: evidence from the Aberdeen children of the 1950s study
}

\author{
Debbie A Lawlor, G David Batty, Susan M B Morton, lan J Deary, Sally Macintyre, \\ Georgina Ronalds, David A Leon
}

J Epidemiol Community Health 2005;59:656-663. doi: 10.1136/jech.2004.030205

\begin{abstract}
See end of article for authors' affiliations

.....................

Correspondence to:

$\operatorname{Dr} D$ A Lawlor, Department

of Social Medicine

University of Bristol,

Canynge Hall, Whiteladies

Road, Bristol BS8 2PR, UK;

d.a.lawlor@bristol.ac.uk

Accepted for publication 14 February 2005
\end{abstract}

\begin{abstract}
Objective: To identify the early life predictors of childhood intelligence.
Design: Cohort study of 10424 children who were born in Aberdeen (Scotland) between 1950 and 1956.

Results: Social class of father around the time of birth, gravidity, maternal age, maternal physical condition, whether the child was born outside of marriage, prematurity, intrauterine growth, and childhood height were all independently associated with childhood intelligence at ages 7, 9, and 11. The effect of social class at birth was particularly pronounced, with a graded linear association across the distribution even with adjustment for all other covariates ( $p<0.001$ for linear trend). Those from the lowest social class (V) had intelligence scores that were on average 0.9-1.0 of a standard deviation lower than those from the higher groups (I and II) at each of the three ages of intelligence testing. Collectively, the early life predictors that were examined explained $16 \%$ of the variation in intelligence at each age. Conclusions: Father's social class around the time of birth was an important predictor of childhood intelligence, even after adjustment for maternal characteristics and perinatal and childhood factors. Studies of the association of childhood intelligence with future adult disease need to ensure that the association is not fully explained by socioeconomic position.
\end{abstract}

intellectual ability. ${ }^{21-24}$ Socioeconomic position itself may be influenced by parental intelligence, which will be linked to childhood intelligence through both genetic and environmental pathways. ${ }^{25}$ While a number of studies have found exposures, such as birth weight, to be associated with childhood intelligence after adjustment for indicators of socioeconomic position, ${ }^{10}$ few previous studies have examined the independent effects of a range of exposures. Furthermore, previous studies have tended to report associations with intelligence test results measured at just one point in time and have therefore been unable to discover if early life factors operate differently at different ages. Using six waves of the US national longitudinal survey of youth-childhood data, Boardman et al reported independent effects of low birth weight, ethnicity, and social and economic characteristics on childhood intelligence. ${ }^{20}$ They also reported that the effect of low birth weight on intelligence seemed to be more noticeable at younger ages. Effects of maternal factors or complications of pregnancy were not assessed in that study and although associations were assessed at different ages these were on a cross sectional sample of different age groups rather than examining whether predictors differed in their effect on intelligence measured within the same cohort of children as they aged.

The aim of this study is to identify independent early life predictors of childhood intelligence measured at ages 7, 9, and at age 11 in a large population based cohort of children who attended primary school in Aberdeen, Scotland in the 1960s.

\section{METHODS}

Figure 1 summarises how the cohort and sample used in this study were obtained from linked data sources. Data from the Aberdeen children of the 1950s cohort study were used. Described in detail elsewhere, ${ }^{26}$ the cohort is based on participants in the Aberdeen child development survey (ACDS), ${ }^{27}$ which was specifically concerned with determining the perinatal and early life determinants of mental

These exposures are interrelated and, to some extent, may reflect the broad effects of poor socioeconomic position on 
subnormality. ${ }^{27}{ }^{28}$ It consists of 12150 children who were born in Aberdeen between 1950 and 1956 for whom comprehensive information was abstracted from the Aberdeen Maternity Hospital records about the course of their mother's pregnancy and the children's physical characteristics at birth and linked to their school records and ACDS results. ${ }^{27}$

\section{Assessment of childhood intelligence}

Throughout the 1950s in Scotland, tests of intelligence were routinely given to children at 7,9 , and 11 years of age and results for members of the children of the 1950s cohort were linked to their 1962 survey data (fig 1) ${ }^{26}$ The tests used at age 7 were the Moray House picture intelligence test numbers 1 or 2 and, at age 9, the Schonell and Adams essential intelligence tests form A or B. ${ }^{26}$ The tests at age 11 included a battery of Moray House tests: two ability tests (verbal reasoning 1 and 2) and two attainment tests (arithmetic, English). ${ }^{26}$ Associations with scores in the latter group of tests were essentially the same, therefore only data for the mean of the two verbal reasoning tests at age 11 were included in the analyses. All intelligence tests were taken within six months of the child's 7th, 9th, and 11th birthday respectively. Tests were age standardised with means of 100 and standard deviations of 15 for Scotland as a whole.

\section{Assessment of predictors of childhood intelligence}

Maternal gravidity (number of pregnancies), height at the time of her pregnancy (nearest inch), whether the child was born outside of marriage, age at the birth of the child, paternal occupation at the time of birth, pregnancy induced hypertension (pre-eclampsia or gestational hypertension), antepartum haemorrhage, artificial rupture of membranes, mode of delivery, birth weight, and gestational age were abstracted from Aberdeen Maternal and Neonatal Database at the time of the 1962 survey. ${ }^{26}$ The participants' intrauterine growth rate was estimated by calculating sex and gestational age (in weeks) standardised z (standard deviation) scores. The father's occupation at birth was classified according to the 1950 registrar general's classification. ${ }^{29}$ Based on their opinion of the mother's physical health and vitality, senior obstetricians classified the women at antenatal care clinics into one of five categories (A denoting very good physical grade; E denoting very poor). Because of the small numbers in the extreme categories this variable was collapsed to three groups. Maternal education was only recorded in the maternity hospital database for women in their first pregnancy; it is therefore only available for a minority $(29 \%)$ of the participants. Among this group, maternal education was classified as left at minimal school leaving age (14 years for those born before April 1933 and 15 for those born later), completed secondary school, completed further education course, completed university degree. Because very few of the participants' mothers had education beyond the minimum leaving age, we dichotomised this variable into those with secondary school or greater education compared with those who left at the minimum leaving age.

The child's height and weight were measured routinely on school entry and results for members of the children of the 1950s cohort were linked to their 1962 survey data. Age and sex standardised $\mathrm{z}$ scores, based on three month age categories, were derived for height, weight, and body mass index. In addition the number of siblings that each child had at the time that the 1962 survey was conducted was recorded.

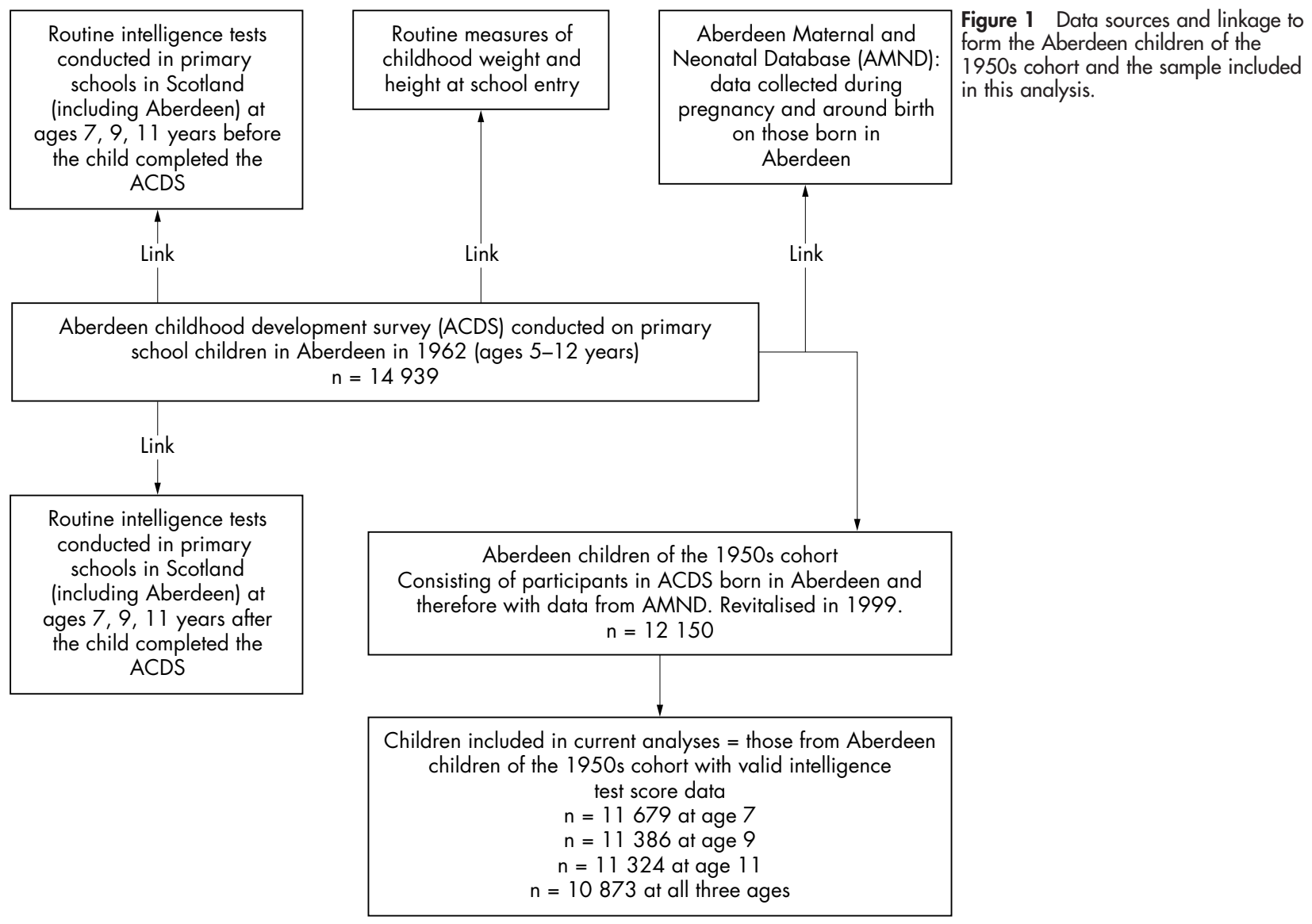


Table 1 Unadjusted associations of early life characteristics with intelligence at age 7 years among 11679 participants with intelligence scores

\begin{tabular}{|c|c|c|c|c|c|}
\hline & & $\mathbf{N}^{*}$ & Mean (SD) & Mean difference $(95 \% \mathrm{Cl})$ & p Value \\
\hline \multicolumn{6}{|l|}{ Parental characteristics } \\
\hline \multirow[t]{5}{*}{ Social class at birth } & I and || & 1031 & $119.2(14.7)$ & ref & $<0.001$ \\
\hline & III NM & 1301 & $112.9(15.6)$ & $-6.32(-7.59,-5.05)$ & \\
\hline & III $M$ & 5185 & $107.5(16.0)$ & $-11.75(-12.79,-10.71)$ & \\
\hline & IV & 1643 & $102.8(14.8)$ & $-16.43(-17.64,-15.22)$ & \\
\hline & $V$ (lowest) & 1920 & $100.4(15.2)$ & $-18.81(-19.98,-17.63)$ & \\
\hline \multirow[t]{5}{*}{ Gravidity } & 1 & 3812 & $109.4(16.2)$ & ref & $<0.001$ \\
\hline & 2 & 3374 & 108.5 (16.3) & $-0.87(-1.62,-0.13)$ & \\
\hline & 3 & 2126 & $106.2(16.3)$ & $-3.14(-4.00,-2.29)$ & \\
\hline & 4 & 1169 & 103.9 (16.2) & $-5.50(-6.56,-4.45)$ & \\
\hline & $\geqslant 5$ & 1198 & $100.1(15.2)$ & $-9.32(-10.37,-8.27)$ & \\
\hline \multirow[t]{2}{*}{ Birth outside marriage } & No & 11181 & $107.3(16.4)$ & ref & $<0.001$ \\
\hline & Yes & 498 & $100.9(15.5)$ & $-6.39(-7.86,-4.93)$ & \\
\hline \multirow{6}{*}{$\begin{array}{l}\text { Maternal age at birth } \\
\text { (years) }\end{array}$} & $15-19$ & 530 & $102.1(15.4)$ & ref & $<0.001$ \\
\hline & $20-24$ & 3656 & $105.4(15.8)$ & $3.22(1.74,4.71)$ & \\
\hline & $25-29$ & 3639 & $108.0(16.5)$ & $5.84(4.35,7.33)$ & \\
\hline & $30-34$ & 2467 & $108.5(16.7)$ & $6.40(4.86,7.93)$ & \\
\hline & $35-39$ & 1050 & 108.8 (16.7) & $6.65(4.95,8.36)$ & \\
\hline & $\geqslant 40$ & 337 & $107.3(16.7)$ & $5.17(2.94,7.40)$ & \\
\hline \multirow[t]{6}{*}{ Maternal height (inches) } & $\leqslant 60$ & 2993 & $104.1(16.3)$ & ref & $<0.001$ \\
\hline & 61 & 1855 & $106.1(16.2)$ & $2.02(1.08,2.96)$ & \\
\hline & 62 & 2080 & $107.5(16.1)$ & $3.48(2.57,4.39)$ & \\
\hline & 63 & 1702 & $108.0(16.7)$ & $3.93(2.97,4.90)$ & \\
\hline & 64 & 1433 & $109.1(15.9)$ & $5.00(3.97,6.02)$ & \\
\hline & $\geqslant 65$ & 1616 & $110.4(16.4)$ & $6.30(5.31,7.28)$ & \\
\hline \multirow[t]{3}{*}{ Maternal physical condition } & Very good or good & 4773 & $109.8(16.0)$ & ref & $<0.001$ \\
\hline & Mediocre & 3228 & $105.3(16.1)$ & $-4.47(-5.18,-3.76)$ & \\
\hline & Very bad or bad & 797 & $99.9(15.2)$ & $-9.84(-11.04,-8.65)$ & \\
\hline \multicolumn{6}{|l|}{ Pregnancy characteristics } \\
\hline Pregnancy induced & No & 9702 & $106.7(16.4)$ & ref & $<0.001$ \\
\hline & Yes & 1977 & $109.0(16.4)$ & $2.35(1.56,3.14)$ & \\
\hline \multirow[t]{2}{*}{ Antepartum haemorrhage } & No & 11416 & $107.1(16.4)$ & ref & 0.003 \\
\hline & Yes & 263 & $104.1(17.9)$ & $-3.00(-5.01,-0.99)$ & \\
\hline \multirow[t]{2}{*}{ Artificial rupture membranes } & No & 9782 & $106.8(16.4)$ & ref & 0.002 \\
\hline & Yes & 1897 & $108.2(16.6)$ & $1.30(0.50,2.11)$ & \\
\hline \multirow[t]{4}{*}{ Method of delivery } & Normal vaginal & 10320 & $106.8(16.4)$ & ref & $<0.001$ \\
\hline & Forceps & 761 & $110.4(16.4)$ & $3.63(2.42,4.83)$ & \\
\hline & Caesarean section & 340 & $111.8(15.1)$ & $5.01(3.25,6.78)$ & \\
\hline & Other assisted delivery & 257 & $102.9(16.7)$ & $-3.88(-5.91,-1.86)$ & \\
\hline \multicolumn{6}{|l|}{ Birth characteristics } \\
\hline \multirow[t]{3}{*}{ Gestational age (weeks) } & $<37$ & 737 & $103.0(16.7)$ & $-5.17(-6.41,-3.96)$ & $<0.001$ \\
\hline & $37-40$ & 7521 & $108.2(16.1)$ & & \\
\hline & $>40$ & 1095 & $107.4(16.4)$ & $-0.75(-1.51,0.02)$ & \\
\hline Birth weight (kg) & Per kg & 11658 & & $4.21(3.64,4.79)$ & $<0.001$ \\
\hline \multicolumn{6}{|l|}{$\begin{array}{l}\text { Birth weight z score } \\
\text { Childhood characteristics }\end{array}$} \\
\hline Height z score & Per SD & 11389 & & $3.36(3.06,3.65)$ & $<0.001$ \\
\hline Weight $\mathrm{z}$ score & Per SD & 11389 & & $1.75(1.45,2.04)$ & $<0.001$ \\
\hline BMI z score & Per SD & 11389 & & $-0.11(-0.41,0.19)$ & 0.47 \\
\hline Number of siblings at time & 0 & 1078 & $111.5(17.0)$ & ref & $<0.001$ \\
\hline \multirow{4}{*}{ of 1962 survey } & 1 & 3525 & $111.2(15.7)$ & $-0.27(-1.35,0.80)$ & \\
\hline & 2 & 2952 & $108.0(15.9)$ & $-3.56(-4.66,-2.46)$ & \\
\hline & 3 & 2001 & $104.3(15.7)$ & $-7.25(-8.43,-6.09)$ & \\
\hline & $\geqslant 4$ & 2107 & $99.2(15.2)$ & $-12.28(-13.44,-11.12)$ & \\
\hline
\end{tabular}

\section{Statistical methods}

Of the 12150 participants, 11679 (96\%) had intelligence scores at age 7, 11386 (94\%) had intelligence scores at age 9, and 11324 (93\%) had scores at age 11, and 10873 (90\%) had intelligence scores at all three ages (fig 1). In the analyses presented in this paper for each intelligence score all those with data at the age being considered are included (that is, for results concerned with intelligence scores at age 7, 11679 participants are included in the analyses). When we repeated the analyses only including those with results on all three intelligence scores (that is, 10 873) the results were essentially unchanged from those presented.

Linear regression was used to estimate mean differences and $95 \%$ confidence intervals of each measure of intelligence across exposure categories. A series of multivariable linear regression models was undertaken to assess the independent effects of each predictor. Among those with intelligence test data, for most of the predictors that we considered (excluding maternal education as discussed above) between $96 \%$ and $100 \%$ of the participants had complete data. There were two exceptions to this. For sex and gestational age adjusted birth weight z score data were available on $90 \%$ and for maternal physical characteristics data were available on $75 \%$. We therefore used multiple imputation using all other variables in the analysis dataset (that is, all predictor variables and the outcomes) to impute values for the missing data for birth weight $\mathrm{z}$ score and maternal physical condition. ${ }^{30}$ We used switching regression as described by Royston, ${ }^{30}$ and carried out 20 cycles of regression switching and generated five imputation datasets. With these imputations $92 \%-93 \%$ of the 


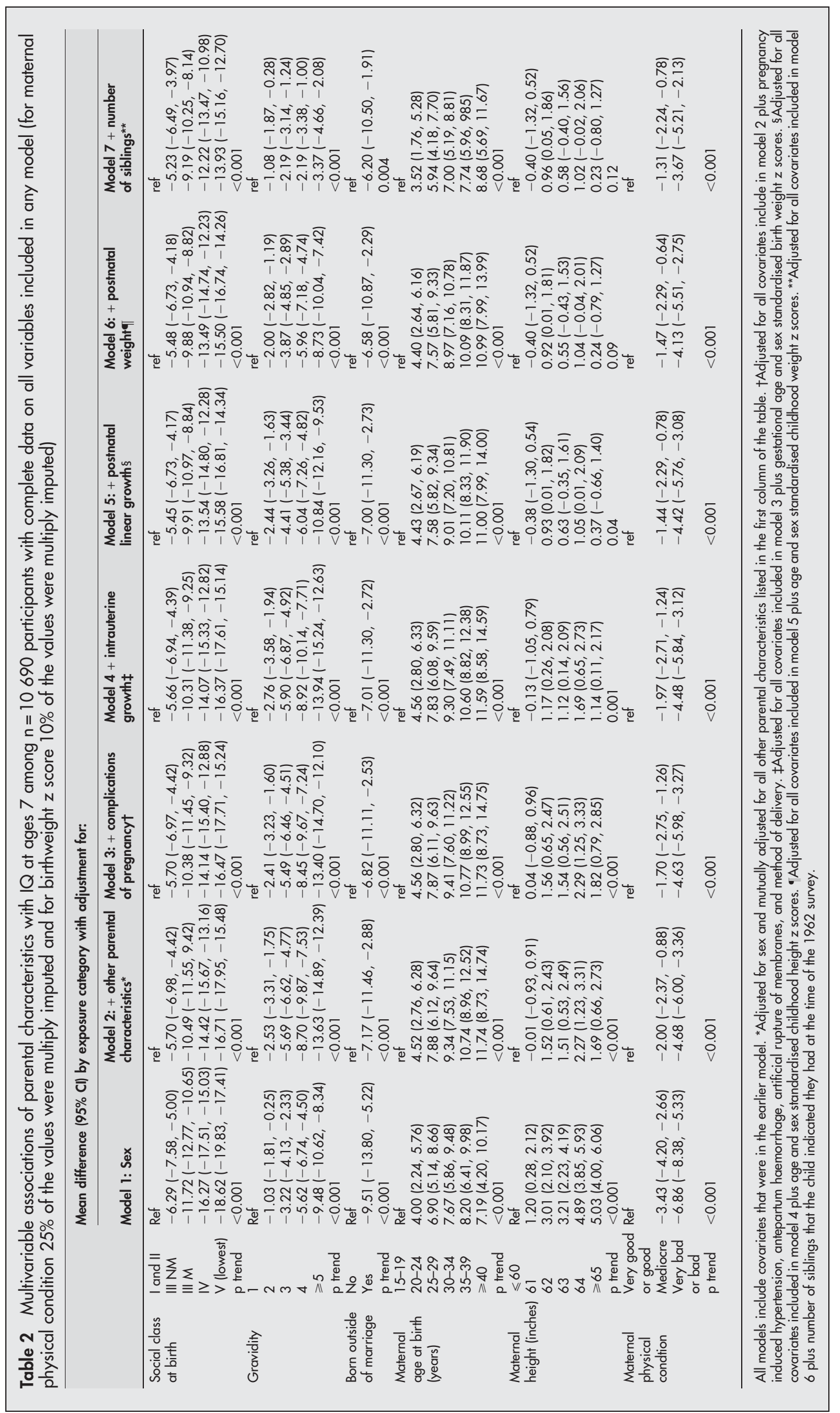


participants with intelligence test scores at each of the three ages had complete data on all potential predictors. The multivariable results presented in this paper are based on analyses using imputed values for the birth weight $\mathrm{z}$ score and maternal physical condition. In addition to these analyses we undertook sensitivity analyses in which we conducted all of the multivariable analyses solely on those people with complete data on all predictor variables and intelligence measured at each age (58\%). The results using multiple imputed data did not differ substantively from those on the complete data subset, although the former were more precisely estimated than the latter.

In the regression models, birth weight and childhood height, weight and body mass index z scores were entered as continuous variables. All other variables were either binary or were entered as indicator variables in the categories presented in table 1 . We examined stratified results and computed likelihood ratio tests to assess interactions. We used robust standard errors when computing $\mathrm{p}$ values and 95\% confidence intervals, to take account of any nonindependence between siblings in the cohort. All analyses were conducted using Stata version 8.0 (Stata, TX).

\section{RESULTS}

The mean (SD) intelligence scores for cohort members were 107.1 (16.4) at age 7, 111.3 (17.0) at age 9, and 99.4 (13.9) at age 11. Intelligence scores were slightly higher for females than males at all ages: for example at age 7 the mean (SD) for females was 107.4 (16.5) and for males was 106.7 (16.3), $\mathrm{p}=0.02$.

Table 1 shows mean intelligence scores at age 7 and mean differences by exposure categories. In these unadjusted analyses all of the predictor variables that we examined, with the exception of body mass index at school entry, were associated with intelligence. The directions and magnitudes of these crude associations were essentially the same for intelligence at 9 and 11 (results not shown). At all ages of assessment the positive relations of childhood weight to intelligence was stronger among females than males (all $\mathrm{p}$ values for interactions $<0.01$ ). The gradient between childhood height and intelligence was also steeper for females than males, the interaction reaching statistical significance for intelligence at age $7(p=0.001)$, but not 9 $(p=0.12)$ or $11(p=0.08)$. There were no other interactions with sex for any exposures.

Table 2 shows the multivariable associations of parental characteristics with intelligence at age 7 . These multivariable analyses are conducted on 10960 (92\% of the participants with intelligence test scores at age 7) participants with complete data on all covariates after multiple imputation of birth weight $\mathrm{z}$ scores and maternal physical condition in pregnancy. Associations with intelligence at age 9 and 11 were essentially the same as at these two ages (data not shown). Paternal social class at birth remained strongly inversely and linearly associated with intelligence at all ages even with adjustment for all other covariates. In adjusted models, children from the lowest social class (group V) had intelligence scores that were on average almost 14 points lower than those in the most advantaged social classes (groups I and II), equivalent to a 0.9 standard deviation difference. For intelligence at age 9 and 11 years the difference was equivalent to 0.9 and 1.0 standard deviation lower, respectively.

Associations between complications of pregnancy and intelligence at all three ages attenuated to the null with adjustment for parental characteristics (all p values $>0.2$ ). The sex adjusted difference in intelligence at age 7 between those born prematurely ( $<37$ weeks) and all other children was -5.11 points $(-6.22,-4.00)$. With additional adjustment for all parental characteristics this attenuated to -3.42 $(-4.53,-2.31)$. Further adjustment for characteristics of pregnancy, birth weight, and childhood characteristics (childhood weight and height and number of siblings) did little to change this difference. A positive association between birth weight and intelligence measured at each age remained even with adjustment for all other potential predictors considered (as listed in column 1 of table 1 -note, childhood weight, and height but not body mass index were included in this model). Considering these effects with respect to birth weight in the fully adjusted models (including gestational age), a $100 \mathrm{~g}$ increase in birth weight would on average be associated with an increase of $0.21(0.17,0.25)$ in intelligence score at age 7 , of $0.20(0.16,0.24)$ at age 9 , and of $0.20(0.15$, 0.30 ) at age 11 . The effect of birth weight did not vary by quarters of the childhood anthropometric measures and there was no statistical evidence of interactions between birth weight and childhood height, weight, or body mass index in their associations with intelligence at any age (all $p$ values $>0.5$ ).

The positive association between childhood height and intelligence remained for both females and males even with adjustment for all potential confounding factors, although the strength of the effect was greater in females than males ( $p$ interaction in the fully adjusted model $=0.008$ ) (table 3 ). Among females, childhood weight and body mass index were positively associated with intelligence in models with full adjustment for all potential confounding factors but there were no associations among males ( $p$ for interaction with sex

Table 3 Multivariable associations of childhood height, weight, and body mass index with IQ score at age 7

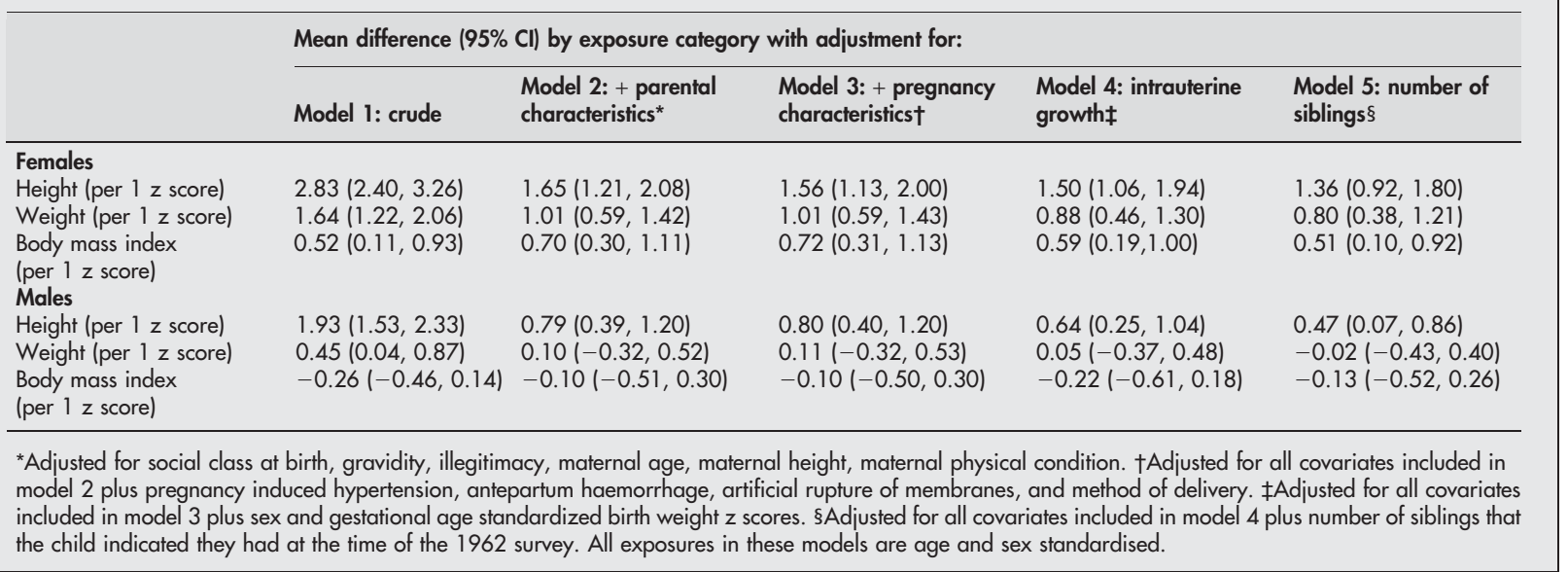


in fully adjusted models for weight $=0.002$ and for body mass index $=0.01$ ) (table 3 ). Results for intelligence at ages 9 and 11 were similar.

Among the 3531 study participants with data on maternal education, 3397 (96\%) had complete data on all potential covariates after multiple imputation of birth weight $\mathrm{z}$ score and maternal physical condition. Children born to mothers who had completed secondary school education and/or higher had higher intelligence scores at age 7 than those who were born to mothers who left at the minimum school leaving age ( $\operatorname{sex}$ adjusted difference $=8.72(7.09,10.35)$ ); similar results were found at ages 9 and 11 . The strong graded association between paternal social class at birth and intelligence remained at all ages even with adjustment for maternal education (all p values for linear trend $<0.001$ ). Among this subgroup of participants the fully adjusted association comparing intelligence at age 7 among those whose fathers were in social class $\mathrm{V}$ with those in social class I and II was $-13.59(-16.39,-10.79)$ (a result very similar to that presented in the final column of table 2). With additional adjustment for maternal education this was not substantively changed: $-12.01(-14.80,-9.22)$. However, adjustment for paternal social class at birth resulted in substantial attenuation of the association between maternal education from $6.28(4.63,7.92)$, with adjustment for all covariates except social class, to $3.80(2.11,5.49)$ with additional adjustment for social class. Associations with intelligence at 9 and 11 years were similar to those at age 7 .

Among the participants with data on all possible explanatory variables (excluding maternal education) paternal social class at birth explained $9 \%$ of the variation in intelligence at ages 7 and 9 , and $10 \%$ of the variation at age 11 . Some of this effect was mediated through other explanatory variables. All other potential explanatory factors considered together (excluding paternal social class) explained $10 \%$ of the variation in intelligence at ages 7 and 11 and $9 \%$ at age 9 . When parental social class was added to these models the amount of variation explained at each age increased to $16 \%$ at all three ages. In the subgroup with data on maternal education all potential predictors including maternal education (but excluding paternal social class) together explained $9 \%$ of the variation in intelligence at all three ages; the addition of paternal social class increased this to $16 \%$. In these models childhood height and weight were included, but not body mass index.

\section{DISCUSSION}

In this study, social class of father around the time of birth, gravidity, maternal age, maternal physical condition, whether the child was born outside of marriage, prematurity, intrauterine growth, and childhood height were all independently associated with childhood intelligence. The effect of paternal social class was particularly notable as it was graded, strong, and independent of other parental, perinatal, and childhood characteristics for which we had data. All of the early life predictors that we examined had associations with intelligence at three ages $(7,9$, and 11$)$ that were in the same direction and of a similar magnitude. Taken together, the early life predictors that we examined explained $16 \%$ of the variation in intelligence at each age.

Our results are consistent with previous studies showing that childhood intelligence is related to socioeconomic position. ${ }^{21-23}{ }^{31}$ Of note poverty, and in particular long term poverty, was associated with lower intelligence test scores among children in the US national longitudinal study of youth in whom intelligence was tested in the 1980s (that is, a more contemporary population than those included in our study). ${ }^{31}$ In that study the association between poverty and intelligence was independent of adjustment for maternal education, family structure, maternal behaviours during pregnancy, infant health, nutritional status, or age of mother at first birth, which is consistent with our finding of an independent association of social class at birth with childhood intelligence after adjustment for other parental characteristics, complications of pregnancy, intrauterine and childhood growth. Our results are also consistent with studies showing a social gradient in extreme mental impairment, including the first results from the present study population, which found pronounced social gradients in the prevalence of mental subnormality when defined as children formally diagnosed and institutionalised and/or those with intelligence test scores below 70 points. ${ }^{28}$

Socioeconomic position at birth is unlikely to have a direct effect on childhood intelligence; its effect is most likely mediated via a number of different pathways including, maternal and other factors affecting intrauterine growth and development, infant and childhood nutrition, living conditions, intellectual stimulation at home, patterns of socialisation, access to educational materials and quality of schooling. We found that the association between father's occupational social class at birth and childhood intelligence persisted even with adjustment for a wide range of other potential mediating factors, including intrauterine growth and childhood anthropometric measures, which to some extent would reflect intrauterine and postnatal nutrition. However, we do not have information to assess the importance of stimulation in the home, parenting style, or home environment on our association between social class at birth and childhood intelligence. These factors may explain the remaining association in our study. In the US national longitudinal survey of youth the association between family poverty (income below the official poverty line) and childhood intelligence was completely mediated by four latent variables representing cognitive stimulation in the home, parenting style, physical environment in the home, and poor child health at birth. ${ }^{24}$ Our results and those of others ${ }^{21}$ do not suggest that childhood health at birth (as measured by birth weight and prematurity) or complications of pregnancy that would affect childhood health at birth are important mediators in the association between socioeconomic position and childhood intelligence.

Parental intelligence scores and educational attainment influence childhood intelligence, ${ }^{25}$ with modest correlations (0.4) between parent and offspring in general intelligence scores. ${ }^{32}$ It is possible, therefore, that the association between social class at birth and childhood intelligence reflects the association between parental and offspring intelligence. In this study we had no measures of parental intelligence and data on maternal education were available on less than one third of the participants. Among this subgroup the strong graded association between paternal social class at birth and intelligence in childhood was not explained by maternal education. This may suggest father's occupational social class affects childhood intelligence because it is the main determinant of family living standards, and that family living standards are more important determinants of childhood intelligence than parental intelligence. However, we would be cautious of making this conclusion based on our data. Firstly, we have no information of paternal intelligence or education. Secondly, our measure of maternal education is on a subsample, and thirdly, maternal education in this study reflects educational attainment among women who were born between 1910 and 1930 and this may not be a good proxy of their intelligence.

Children who were born prematurely have been found in a large number of studies to have lower childhood intelligence than those born at or beyond term, ${ }^{10}$ and our results are consistent with these findings. A recent systematic review 


\section{What this paper adds}

- Paternal social class around the time of birth, gravidity, maternal age, maternal physical condition, whether the child was born outside of marriage, prematurity, intrauterine growth, and childhood height are all independently associated with childhood intelligence.

- The effect of social class at birth is particularly noticeable, with a graded linear association across the distribution even with adjustment for all other covariates available in this study.

- Studies of the association of childhood intelligence with future adult disease need to ensure that the association is not fully explained by socioeconomic position.

concluded, in agreement with our findings, that there was a weak positive association between birth weight across its population distribution and childhood intelligence that was independent of socioeconomic position. ${ }^{10}$ We found that the magnitude of the association between birth weight and childhood intelligence was the same for intelligence measured at age 7,9 , or 11 , which somewhat contradicts the findings by Boardman et al that the effect of extreme low birth weight $(<1500 \mathrm{~g})$ on childhood intelligence was more noticeable at younger compared with older ages. ${ }^{20}$ The differences between that study and our findings may be because of the difference in exposure measurement (we assessed the effect of birth weight across its distribution rather than a dichotomy of low birth weight), or because in our study childhood intelligence was measured in the same cohort of children at different ages whereas in the US study by Boardman et al the association was measured at the same time in children of different ages.

The only previously published study, of which we are aware, to have examined the combined effects of intrauterine and postnatal growth, found that birth weight and height were both independently associated with intelligence. ${ }^{19}$ These findings are consistent with our own. They suggest that factors affecting intrauterine growth and postnatal linear growth, such as intrauterine and childhood nutrition, affect childhood intelligence. In that study, ${ }^{19}$ results were presented for both sexes combined and we are therefore unable to determine whether the association between childhood height was greater for females compared with males as it was herein. All subgroup analyses should be treated with caution until they have been shown to be consistently replicated in a number of studies. ${ }^{33}$ As with other studies we found intelligence scores among female children to be higher than those among males. ${ }^{10} 20$

\section{Study limitations}

In these analyses we related intelligence measured at three ages to a large number of potential predictor variables and because of the large number of statistical tests necessarily conducted, some of the associations may have arisen by chance alone, although the consistency with other studies would argue against this. As this study was conducted on children in the 1960s attending schools in Aberdeen, its findings may not be directly relevant to children from other areas or to contemporary children. Aberdeen has had a very high reputation for good quality education throughout the 20th century. In a 1950s statistical account of Aberdeen it was stated that "Aberdeen has always valued education as a factor of the highest importance in daily life, and it has made liberal provision for achievement of its ideals". ${ }^{34}$ This might explain the fact that the mean intelligence test results at ages
7 and 9 (107.1 and 111.3 respectively) for children in this cohort were somewhat higher than the average for Scotland as a whole. If educational environment both in the home and in school in part explain the association between social class at birth and childhood intelligence that we have found then this association in other areas with poorer quality education systems may be even stronger than those that we have found. For some associations such as the independent association of prematurity with intelligence, the impact is likely to be similar between geographical areas and over time. However, it could be argued that those in the lowest social groups and with the youngest mothers in the 1950s are likely to have suffered more extreme deprivation than contemporary infants. For example, Thompson reported pronounced differences between pregnant women and mothers in Aberdeen in 1951 and those in 1985. ${ }^{35}$ There was an acute housing shortage in Aberdeen at that earlier period and many young couples and their children lived with their parents or in very overcrowded inner city tenements. Food rationing was also still in force in the early 1950s. However, the associations that we have presented were graded and linear across the exposure distribution rather than being a threshold effect, suggesting that associations would still be apparent in contemporary populations. Furthermore, our findings are consistent with studies in more contemporary populations (1980s/90s) in which pronounced associations between indicators of socioeconomic position and childhood intelligence have been reported..$^{22} 3136$

In conclusion we have found that paternal social class around the time of birth, maternal age, gravidity, maternal physical condition, whether the child was born outside of marriage, prematurity, intrauterine growth, and childhood height are all independently associated with childhood intelligence. In particular, we have found a pronounced graded association between paternal social class at birth and childhood intelligence at ages 7, 9, and 11 among children born in the 1950s. Although studies of the association of childhood intelligence with adult morbidity and mortality have largely shown these associations to be independent of childhood socioeconomic position, this has largely been determined by adjustment for socioeconomic position in multivariable models. Because of the very strong association between social class around the time of birth and childhood intelligence shown here we would recommend that future studies of the association between childhood intelligence and adult disease and mortality present results stratified by socioeconomic position and also consider whether socioeconomic position might still explain their results, for example if intelligence has been measured with greater accuracy than socioeconomic position.

\section{ACKNOWLEDGEMENTS}

D A Lawlor, G D Batty, S M Morton, and D A Leon developed the study aim and design and were involved in the revitalisation of the cohort. D A Lawlor undertook the analyses and together with G D Batty and S M Morton wrote the first draft of the paper. I J Deary contributed to developing the study aim and writing the final version of the paper. S Macintyre was involved in the revitalisation of the cohort and contributed to the final version of the paper. G Ronalds contributed to the intellectual development and writing of the final version of the paper.

\section{AUTHOR CONTRIBUTIONS}

We are grateful to Raymond Illsley for providing us with the data from the Aberdeen child development survey and for his advice about the study. Graeme Ford played a crucial part in identifying individual cohort members and in helping us start the process of revitalisation. Doris Campbell, George Davey Smith, Marion Hall, Bianca de Stavola, David Godden, Di Kuh, Glyn Lewis, and Viveca Östberg collaborated with the authors to revitalise the cohort. Heather Clark managed the study at the Dugald Baird Centre, Aberdeen with the assistance of 
Margaret Beveridge. We would also like to thank staff at the ISD (Edinburgh), GRO (Scotland), and NHSCR (Southport) for their substantial contributions and John Lemon who undertook the linkage to the Aberdeen Maternity and Neonatal Databank. Finally, we thank the study participants who responded to a mailed questionnaire 40 years after the original survey was completed.

\section{Authors' affiliations}

D A Lawlor, Department of Social Medicine, University of Bristol, UK G D Batty, S Macintyre, MRC Social and Public Health Sciences Unit, University of Glasgow, Glasgow, Scotland

G D Batty, I J Deary, Department of Psychology, University of Edinburgh, Edinburgh, Scotland

S M B Morton, School of Population Health, University of Auckland, Auckland, New Zealand

G Ronalds, D A Leon, Department of Epidemiology and Population Health, London School of Hygiene and Tropical Medicine, UK

Funding: the Aberdeen children of the 1950s study was funded as a component project (G0828205) of a Medical Research Council Cooperative Group Life-course and trans-generational influences on disease risk (G9819083). A project on cognition and adult health in the cohort has been funded by the Chief Scientists Office, Scottish Executive Health Department; this provides G Ronald's salary. D A Lawlor is funded by a UK Department of Health Career Scientist Award. When work on this began, G D Batty was supported by a University of Copenhagen Senior Research Fellowship; he is now funded by a Wellcome Trust Advanced Training Fellowship. I J Deary is the recipient of a Royal Society-Wolfson Research Merit Award. The views expressed in this publication are those of the authors and not necessarily those of any funding body.

Conflicts of interests: none declared.

\section{REFERENCES}

1 Starr JM, Taylor MD, Hart CL, et al. Childhood mental ability and blood pressure at midlife: linking the Scottish mental survey 1932 and the Midspan studies. J Hypertens 2004;22:893-7.

2 Hart CL, Taylor MD, Davey Smith G, et al. Childhood IQ, social class, deprivation, and their relationships with mortality and morbidity risk in later life: prospective observational study linking the Scottish mental survey 1932 and the midspan studies. Psychosom Med 2003;65:877-83.

3 Osler M, Andersen AM, Due P, et al. Socioeconomic position in early life, birth weight, childhood cognitive function, and adult mortality. A longitudinal study of Danish men born in 1953. (Correction appears in J Epidemiol Community Health 2003;57:995) J Epidemiol Community Health 2003;57:681-6.

4 Whalley $\mathrm{L}$, Deary IJ. Longitudinal cohort study of childhood IQ and survival up to age 76. BMJ 2001;322:819.

5 Kuh D, Richards M, Hardy R, et al. Childhood cognitive ability and deaths up until middle age: a post-war birth cohort study. Int J Epidemiol 2004;33:408-13.

6 Batty GD, Deary IJ. Early life intelligence and adult health. Emerging associations, plausible mechanisms, and public health importance. BMJ 2004;329:585-6.

7 Taylor MD, Hart CL, Davey Smith G, et al. Childhood mental ability and smoking cessation in adulthood: prospective observational study linking the Scottish mental survey 1932 and the midspan studies. J Epidemiol Community Health 2003;57:464-5.

8 Turkheimer E, Haley A, Waldron $M$, et al. Socioeconomic status modifies heritability of IQ in young children. Psychol Sci 2003;14:623-8.

9 Turkheimer E. Individual and group differences in adoption studies of IQ. Psychol Bull 1991;110:392-405.

10 Shenkin SD, Starr JM, Deary IJ. Birth weight and cognitive ability in childhood: a systematic review. Psychol Bull 2004;130:989-1013.

11 Breslau N, Chilcoat H, DelDotto J, et al. Low birth weight and neurocognitive status at six years of age. Biol Psychiatry 1996;40:389-97.
12 Sorensen HT, Sabroe S, Olsen J, et al. Birth weight and cognitive function in young adult life: historical cohort study. BMJ 1997;315:401-3.

13 Richards M, Hardy R, Kuh D, et al. Birth weight and cognitive function in the British 1946 birth cohort: longitudinal population based study. BMJ 2001;322:199-203.

14 Shenkin SD, Starr JM, Pattie A, et al. Birth weight and cognitive function at age 11 years: the Scottish mental survey 1932. Arch Dis Childhood 2001;85:189-97.

15 Jefferis BJ, Power C, Hertzman C. Birth weight, childhood socioeconomic environment, and cognitive development in the 1958 British birth cohort study. BMJ 2002;325:305

16 Gordon M, Crouthamel C, Post EM, et al. Psychosocial aspects of constitutional short stature: social competence, behavior problems, selfesteem, and family functioning. J Pediatr 1982;101:477-80.

17 Stabler B, Clopper RR, Siegel PT, et al. Academic achievement and psychological adjustment in short children. The national cooperative growth study. J Dev Behav Pediatr 1994;15:1-6.

18 Stathis SL, O'Callaghan MJ, Williams GM, et al. Behavioural and cognitive associations of short stature at 5 years. Journal of Paediatrics and Child Health 1999;35:562-7.

19 Richards M, Hardy R, Kuh D, et al. Birthweight, postnatal growth and cognitive function in a national UK birth cohort. Int J Epidemiol 2002;31:342-8

20 Boardman JD, Powers DA, Padilla YC, et al. Low birth weight, social factors, and developmental outcomes among children in the United States. Demography 2002;39:353-68.

21 O'Callaghan M, Williams GM, Andersen MJ, et al. Social and biological risk factors for mild and borderline impairment of language comprehension in a cohort of five-year-old children. Dev Med Child Neurol 1995;37:1051-61.

22 McLoyd VC. Socioeconomic disadvantage and child development. Am Psychol 1998;53:185-204.

23 Gomez-Sanchiz M, Canete R, Rodero I, et al. Influence of breast-feeding on mental and psychomotor development. Clin Pediatr 2003;42:35-42.

24 Guo G, Harris KM. The mechanisms mediating the effects of poverty on children's intellectual development. Demography 2000;37:431-47.

25 Rowe DC, Jacobson KC, Van den Oord EJ. Genetic and environmental influences on vocabulary IQ: parental education level as moderator. Child Dev 1999;70:1151-62.

26 Batty GD, Morton SMB, Campbell D, et al. The Aberdeen children of the 1950s cohort study: background, methods, and follow-up information on a new resource for the study of life-course and intergenerational effects on health. Paediatr Perinat Epidemiol 2004;18:221-39.

27 Illsley R, Wilson F. Longitudinal studies in Aberdeen, Scotland. C. The Aberdeen child development survey. In: Mednick S, Baert A, Bachmann B, eds. Prospective longitudinal research. An empirical basis for the primary prevention of psychosocial disorders. Oxford: Oxford University Press, 1981:66-8.

28 Birch HG, Richardson SA, Baird D, et al. Mental subnormality in the community: a clinical and epidemiologic study. Baltimore: Williams and Wilkins, 1970.

29 General Register Office. Classification of occupations 1950. London: General Registrar Office, 1951.

30 Royston P. Multiple imputation of missing values. Stata Journal 2004;4:227-41.

31 Korenman S, Miller J, Sjaastad J. Long-term poverty and child development in the United States: results from the NLSY. Children and Youth Services Review 1995; 17:127-55.

32 Plomin R, Craig I. Genetics, environment and cognitive abilities: review and work in progress towards a genome scan for quantitative trait locus associations using DNA pooling. Br J Psychiatry Suppl 2001;40:s41-8.

33 Lawlor DA, Ebrahim S, Davey Smith G. Is there a sex difference in the association between birth weight and systolic blood pressure in later life? Findings from a meta-regression analysis. Am J Epidemiol 2002; 156:1100-4

34 Mackenzie H. The third statistical account of Scotland. The city of Aberdeen. Edinburgh: Oliver and Boyd, 1953.

35 Thomson B, Hewitt A, Skipper D. Having a first baby-experiences in 1951 and 1985 compared: two social, obstetric and dietary studies of married primigraviddae in Aberdeen. Aberdeen: Aberdeen University Press, 1985.

36 Hofferth SL, Smith J, McLoyd VC, et al. Achievement and behavior among children of welfare recipients, welfare leavers, and low-income single mothers. Journal of Social Issues 2000;56:747-74. 